\title{
Evaluation of short-term geomorphic changes in differently impacted gravel-bed rivers using improved dems of difference
}

\author{
F. Delai, ${ }^{1}$ J. Moretto, ${ }^{1}$ L. Mao, ${ }^{2}$ L. Picco, ${ }^{1}$ M.A. Lenzi ${ }^{1}$ \\ 'Department of Land, Environment, Agriculture and Forestry, University of Padova, Padova, Italy \\ ${ }^{2}$ Department of Ecosystems and Environment, Pontificia Universidad Catolica de Chile, Santiago, \\ Chile
}

\begin{abstract}
The evaluation of the morphological dynamics of rivers is increasingly focusing, in recent years, on the achievement of quantitative estimates of change in order to identify geomorphic trends and forecast targeted restoration actions. Thanks to the development of more effective and reliable survey technologies, more accurate Digital Elevation Models (DEM) can be produced and, through their consequent differencing (DoD), extremely useful geomorphic analyses can be carried out. In this situation, a major role is played by uncertainty, especially in the final volumetric rates of erosion and deposition processes, that may lead to misinterpretation of spatial and temporal changes. This paper aims at achieving precise geomorphic estimates derived from subsequent hybrid (LiDAR and bathymetric points) surface representations. The study areas consist of gravel-bed reaches of two differently impacted fluvial environments, Piave and Tagliamento rivers, that were affected by two severe flood events (Piave, R.I. of 7 and 10 years and Tagliamento, R.I. of 15 and 12 years) in the inter-surveys period. The basic Hybrid Digital Elevation Models (HDTM) were processed accounting for spatially variable uncertainty and consider-
\end{abstract}

Correspondence: Fabio Delai, Department of Land, Environment, Agriculture and Forestry, University of Padova, Italy.

E-mail: fabio.delai@studenti.unipd.it

Key words: DoD, geomorphic changes, gravel bed braided river, LiDAR, Piave River, Tagliamento River.

Acknowledgements: this research was founded by the University of Padua Strategic Research Project PRST08001, "GEORISKS, Geological, morphological and hydrological processes: monitoring, modelling and impact in NorthEastern Italy", Research Unit STPD08RWBY-004; the Italian National Research Project PRIN20104ALME4-ITSedErosion: "National network for monitoring, modeling and sustainable management of erosion processes in agricultural land and hilly-mountainous area"; and The EU SedAlp Project: "Sediment management in Alpine basis: Integrating sediment continuum, risk mitigation and hydropower", 83-4-3-AT, in the framework of the European Territorial Cooperation Programme Alpine Space 2007-2013.

CCopyright F. Delai et al., 2013

Licensee PAGEPress, Italy

Journal of Agricultural Engineering 2013; XLIV(s2):e23

doi:10.4081/jae.2013.s2.e23

This article is distributed under the terms of the Creative Commons Attribution Noncommercial License (by-nc 3.0) which permits any noncommercial use, distribution, and reproduction in any medium, provided the original author(s) and source are credited. ing, beside slope and point density input variables, a novel component measuring the quality of the bathymetric derived points. In fact, since the major changes occur within river channels, the integration of this variable evaluating the precision of the bathymetric channel elevations in the HDTMs, has allowed, through the creation of targeted FIS (Fuzzy Inference System) rules, to obtain reliable geomorphic estimates of change. Volumes and erosion and deposition patterns were then analyzed and compared to outline the different dynamics among the sub-reaches and the two river systems.

\section{Introduction}

The estimation of close-to-real rates of geomorphic changes has become a major issue of river geomorphology in the recent years. Beside qualitative evaluations, the achievement of reliable amounts of erosion and deposition processes represents a great help for identifying the current state of a river environment and plan future management actions. The advances in the different survey technology methods, such as total stations (Fuller et al., 2005), dGPS (Brasington et al., 2003), aerial LiDAR (Devereux and Amable, 2009) and TLS (Milan et al., 2007; Heritage and Milan, 2009), have allowed a quicker acquisition of topographic data over larger extents and with very fine resolutions (Marcus and Fondstad, 2008; Notebaert et al., 2008). Thanks to the development of GIS tools capable to process large datasets, the interpolation of Digital Elevation Models (DTMs) has become the most common procedure to represent and analyze topographic surfaces (Milan et al., 2011). A problem in the reproduction of river environments is featured by the representation of wet areas where, normally, the most significant scour and fill processes take place. Without the use of bathymetric sensors (i.e. bathymetric LiDAR), technologies still characterized by high costs, scarce data quality and relatively rough resolutions (Hilldale and Raff, 2008), the representation of river channels results limiting, since signals undergo absorption by water. To solve these problems, a cost-effective detection method for wet areas can be the calibration of depth-reflectance relationships, using greyscale, colour-scale and multispectral imagery, even considering that they need depth points from a contemporary field survey (Moretto et al., 2012). After achieving precise DEMs, their difference can produce reliable Dems of Difference (DoDs) where scour and fill areas and volumes can be analyzed (Lane et al., 2003). In all this process, a decisive role is played by uncertainty that in wet areas often exceeds the real change (Wheaton et al., 2010). A novel reliable approach introduced by Wheaton et al. (2010) and packaged in a wizard-driven Matlab software application (Geomorphic Change Detection), presents a robust and spatially variable estimation of DEM uncertainty in order to achieve precise rates of geomorphic changes. The cell-by-cell use of a Fuzzy Inference System (FIS) to obtain a spatially variable elevation uncertainty and the modification of the resulting sediment budget on 
the basis of probabilistic spatial coherence of erosion and deposition units are the key innovations of this method (Wheaton et al., 2010).

In the present work we aim at performing and interpreting accurate and reliable estimates of short-term geomorphic changes of study reaches of two differently impacted gravel-bed rivers of North-Eastern Italy: Piave and Tagliamento rivers. Starting from hybrid DTMs (Moretto et al., 2012) derived by integrating LiDAR and colour bathymetry data sources, precise DoDs showing scour and fill estimates will be produced using the Geomorphic Change Detection (GCD) software (Wheaton et al., 2010). The two novel methodological aspects regard: first, the use of hybrid DTMs in a the GCD environment and, second, the creation of an "ad hoc" FIS script where, beside the commonly used slope and point density inputs, a third factor evaluating the accuracy of the bathymetric points (derived using the Moretto et al. 2012 method) used to represent in-channel areas (zones normally featuring the greatest changes) will be presented.

\section{Study areas}

\section{Piave river}

The Piave River basin (drainage area $3900 \mathrm{~km}^{2}$ ) lies in the Eastern Italian Alps. The main channel flows in the south direction for $220 \mathrm{~km}$ from its headwaters to the outlet in the Adriatic Sea, near to Venice. The analyzed portion of the Piave river is located in its middle course and features an average annual precipitation of about $1350 \mathrm{~mm}$ and a very wide gravel bed, characterized by a multithread channel pattern. Two study sub-reaches that have been selected are (drainage area until the Belluno station equal to $1965 \mathrm{~km}^{2}$; Figure 1): Belluno featuring a length of about $2.2 \mathrm{~km}$ and Praloran with a length of $3.2 \mathrm{~km}$. Their morphology is dominated by braided and wandering channel patterns, the slope is around $0.45 \%$, and the $\mathrm{D}_{50}$ ranges between 20 and $50 \mathrm{~mm}$ (Comiti et al., 2011; Kaless et al., 2013).

The Piave river has suffered intense and multiple human impacts which reached their peak between the 1960s and the 1990s with heavy gravel mining activities (Comiti et al.,2011).

\section{Tagliamento river}

The Tagliamento river is a natural gravel-bed river, located in the North-Eastern Italy. It originates at $1195 \mathrm{~m}$ a.s.l. and flows for $178 \mathrm{~km}$ from the Alps to the northern Adriatic Sea, thereby forming a link corridor between the Alpine and the Mediterranean zones. Its catchment covers $2871 \mathrm{~km}^{2}$. It is considered one of the most natural European river environments and its basin is located in one of the wettest areas of Europe, where the annual precipitation can reach $3100 \mathrm{~mm}$ per year. The two study sub-reaches (Figure 2) are located in the piedmont area of the river where the prevalent morphology is braided and the average D50 is equal to $36 \mathrm{~mm}$ (Mao et al., in preparation). The first one, Cornino, features a length of $3 \mathrm{~km}$ while the second, Flagogna, a length of $3.5 \mathrm{~km}$ (Picco et al., submitted).

\section{Materials and methods}

The survey analyses consist in three different data sources acquired before and after the severe flood events (Fig. 3) occurred in NovemberDecember 2010 (Piave, R.I. of 7 and 10 years and Tagliamento, R.I. of 15 and 12 years): LiDAR, dGPS and aerial photos. LiDAR and aerial photo captures were performed in August 2010 (for both rivers) and in February 2011 (for the Piave river) and April 2011 (for the Tagliamento river) by Blom GCR SpA using an OPTECH ALTM Gemini Sensor (flight height $\sim 850 \mathrm{~m}$ ). The data acquisition was carried out with the best weather and low water level conditions and the LiDAR points were filtered from vegetation using the Terrascan software (Terrasolid). The point density was commissioned in function of the required DTM resolution ( $0.5 \mathrm{~m}$ cell-size) accounting for at least two ground points per $\mathrm{m}^{2}$ and the average vertical error was estimated through dGPS points comparison in the final surface models. LiDAR acquisition was associated with a series of RGB aerial images featuring $0.15 \mathrm{~m}$ of pixel resolution. Finally, dGPS points were taken contemporary, covering different morphological units and water stages. Totally, 537 dGPS points in 2010 and 4006 dGPS points in 2011 for the Piave river and 1107 dGPS points in 2010 and 9366 dGPS points in 2011 for the Tagliamento river were surveyed (dGPS average vertical error $\pm 0.025 \mathrm{~m}$ ).

Through the Moretto et al. (2012) method that derives water depths by calibrating a regression model between the Z-detrended dGPS coordinate and the photo colour bands (Red, Green and Blue), bathymetric points for the wet areas and LiDAR filtered points for the dry areas were integrated to build accurate hybrid DTMs (for 2010 and 2011).
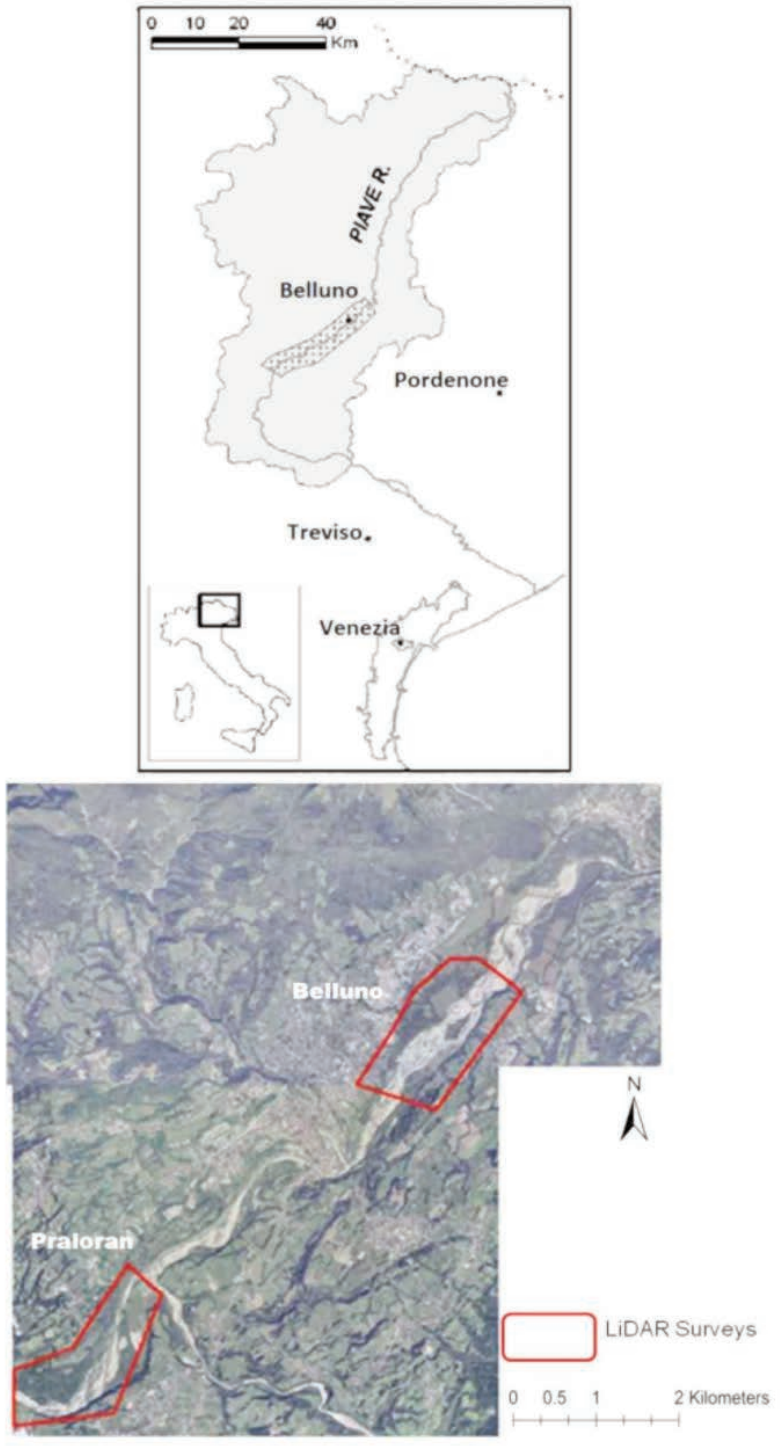

Figure 1. The Piave river basin and (below) the two study sub-reaches, Belluno and Praloran. 


\section{Preparation of Fuzzy Inference System (FIS) variables and rules}

In Matlab environment (Fuzzy Logic application) an "ad hoc" FIS file considering as inputs slope, point density and bathymetric points quality and as output elevation uncertainty was edited. Slope and point density categorical limits (i.e. low, medium, high) were chosen taking into consideration the literature values (Wheaton et al., 2010) and our fluvial environments (gravel-bed rivers) and related field experience. The third input variable, the bathymetric points quality, represents an innovation inasmuch the colour bathymetry derived points (Moretto et al., 2012) that were used to interpolate the wet areas of the DTMs were also evaluated in their accuracy. The achievement of reliable final geomorphic estimates considering the precision of in-channel depths was here considered as fundamental since the most significant scour and fill processes occur in the wet areas. For this input variable, we needed to consider only in-channel elevations so that, beside the common low, medium and high categories, a fourth "out channel" category including all the points elevation of the dry areas was added. The categorical limits of this bathymetric accuracy input feature small differences among the considered years and rivers (Table 1) depending on the number of dGPS points used to calibrate the model (Moretto et al., 2012). All the categorical limit values of this input variable were increased by 10 in order to avoid problems of having negative and "crossing-zero" values in the Fuzzy Logic application. Finally, 36 FIS rules were edited, setting the output qualities of the elevation uncertainty according to Wheaton et al. (2010) as low, average, high and extreme. For details on the FIS logic and procedure we refer to Wheaton et al. (2010).

\section{Preparation of the associated input DTMs}

In ArcGIS 10.0 (ESRI) environment the three DTMs associated to the input variables (slope, point density and bathymetric points quality) were then created for each sub-reach and year (2010 and 2011) using, as basis source, the hybrid DTMs. The slope and point density DTM were interpolated using the correspondent ArcGIS tools. Concerning the "bathymetric points quality" DTM, a surface interpolating in the wet areas the points (increased by 10) derived by the Moretto et al. (2012) procedure and in the dry areas a unique value of $11 \mathrm{~m}$ to include all the outer channel surface was finally built.

\section{Final DoD production using the GCD software}

At this point, the basic hybrid DTMs, the FIS files ("Piave", "Tagliamento 2010" and "Tagliamento 2011" differing only in the class limits of the input variable "bathymetric points quality") and the associated input DTMs (slope, point density and bathymetric points quality) were ready to be run in the Geomorphic Change Detection 5.0 (GCD) software (Wheaton et al., 2010; http://gcd.joewheaton.org). Through the creation of associated uncertainty surfaces derived by the combination of the input DTMs and FIS rules, the basic hybrid DTMs and the error rasters were differenced producing reliable DoDs. Geomorphic changes were calculated, following literature (Wheaton et al., 2010), by using a spatially variable uncertainty thresholded at $95 \%$ C.I. and the Bayesian updating method which accounts for spatial coherent erosion and deposition units ( $5 \times 5$ mobile windows). For details on the GCD software we refer to Wheaton et al. (2010).

\section{Results}

The main results of the study concern the production of precise DoDs and consequent change estimates accounting for uncertainty by

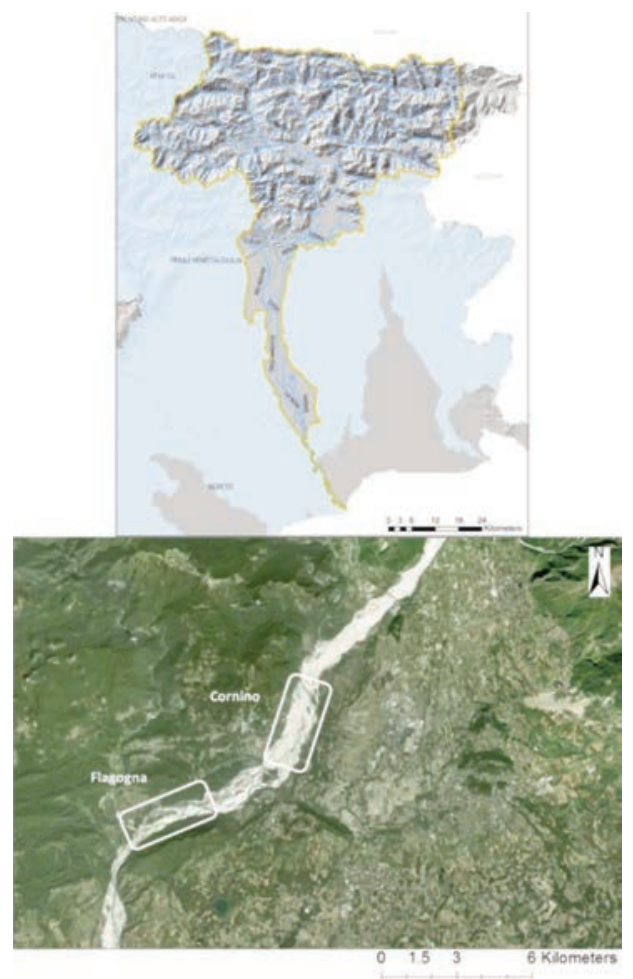

Figure 2. The Tagliamento river basin and (below) the two study subreaches, Cornino and Flagogna.

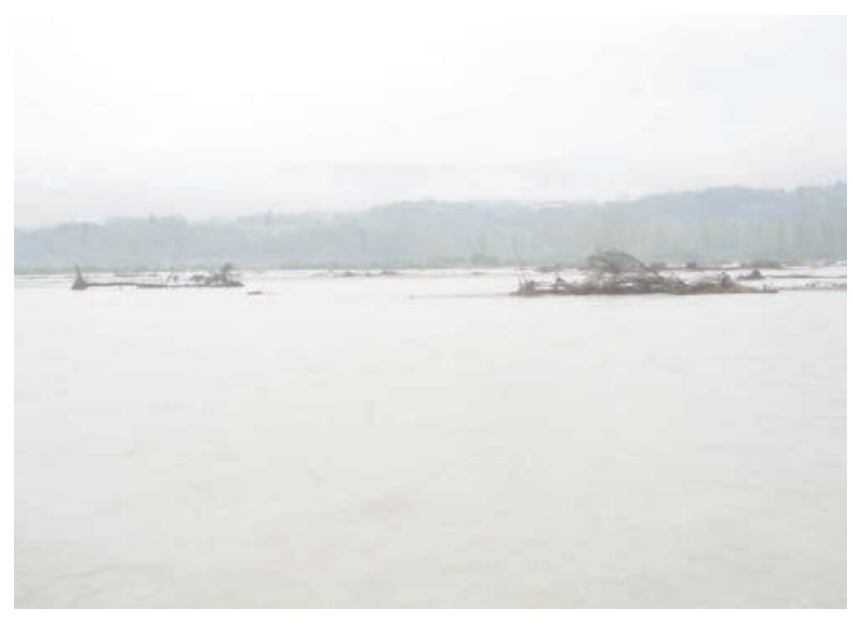

Figure 3. Belluno sub-reach (Piave river) during the flood events of November-December 2010.

Table 1. Original categories and limits used to describe in the FIS file the novel input variable: bathymetric points quality.

\begin{tabular}{lcccccccccccc} 
& \multicolumn{4}{c}{ Piave } & \multicolumn{1}{c}{ Tagliamento 2010} & \multicolumn{1}{c}{ Tagliamento 2011} \\
Low & -3 & -3 & -1.4 & -1.3 & -3 & -3 & -0.8 & -0.7 & -3 & -3 & -1.5 & -1.4 \\
High & -1.4 & -1.3 & -0.3 & -0.2 & -0.8 & -0.7 & -0.25 & -0.15 & -1.5 & -1.4 & -0.3 & -0.2 \\
\hline Medium & -0.3 & -0.2 & 0.25 & 0.3 & -0.25 & -0.15 & 0.25 & 0.3 & -0.3 & -0.2 & 0.25 & 0.3 \\
Out Channel & 0.25 & 0.3 & 1 & 1 & 0.25 & 0.3 & 1 & 1 & 0.25 & 0.3 & 1 & 1 \\
\hline
\end{tabular}


using an innovative multi-input GCD analysis. In Figure 4 we can observe the DoDs of Belluno and Praloran sub-reaches (Piave river). In both models, a first visual inspection underlines a fluid representation of erosion and deposition dynamics, especially in the wet channels that are the areas featuring the major variations. The use of the novel input variable evaluating the precision of the bathymetric derived elevation points seems to help to better define the underwater zones contributing to more reliable scour and fill estimates. The parts of the DoD maps featuring no colors represent either areas where no change has occurred or areas with a too high uncertainty. Even though an accurate filtering process deleting the vegetation interference were carried out in the first phases of data management (using Terrascan software), possible errors due to the residual presence of misleading elevations should be taken into account. Considering the volumetric estimates, as we can observe in Table 2, a comparison between the raw and the spatially-variable thresholded volumes is presented. The estimates obtained using the GCD analysis, improved with the bathymetric quality evaluation input, result more conservative and provided with an accurate uncertainty quantification. In both sub-reaches net erosion has considerably prevailed as a consequence of the flood events of November-December 2010 with an associated error calculation that in Praloran overtakes the estimate of plausible change.

In the case of the Tagliamento river, the DoDs of Cornino and Flagogna sub-reaches (Figure 5) represent, similarly to those of the Piave river, very precisely the geomorphic changes occurred after the 2010 flood events. The alternation of scour and fill areas results very fluid producing a reliable basis for volumetric change estimates. In Table 3 raw and thresholded volumes of erosion and deposition processes and the consequent sediment storage are reported, confirming the conservative output of the GCD analysis accounting for the novel bathymetric quality evaluation. In the first sub-reach, Cornino, net erosion significantly prevails while in Flagogna sub-reach a final difference indicating a predominant deposition is present. Noteworthy is the comparison of the sediment volumes mobilized by the two rivers: the Tagliamento features a significantly higher order of magnitude in respect to the Piave.

\section{Discussion}

The detection and quantification of the geomorphic changes occurred as a consequence of the 2010 flood events by using an improved GCD analysis have shown precise and meaningful results. The use of "basis" hybrid DTMs (LiDAR and colour bathymetry derived) and the creation of an ad hoc FIS file including an innovative input that evaluates the accuracy of the wet channel points derived by colour bathymetry (Moretto et al., 2012) have contributed to improve the reliability of the volumetric estimates. In fact, considering the precision of

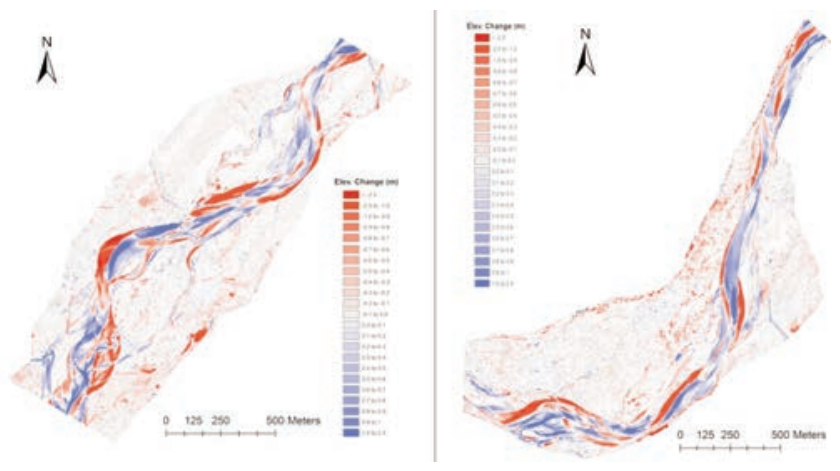

Figure 4. DoDs of Belluno and Praloran sub-reaches (Piave river) obtained using the improved GCD analysis.

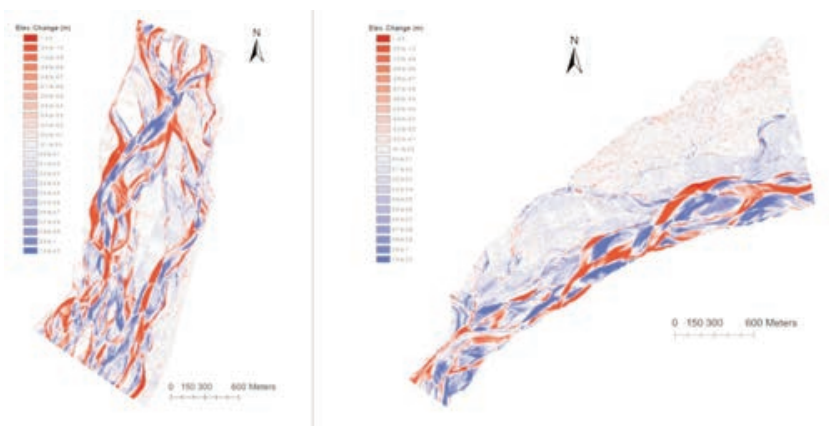

Figure 5. DoDs of Cornino and Flagogna sub-reaches (Tagliamento river) obtained using the improved GCD analysis.

Table 2. Raw and thresholded volumes of geomorphic changes accounting for uncertainty for the Piave river.

\begin{tabular}{|c|c|c|c|c|c|c|}
\hline & \multicolumn{3}{|c|}{ Belluno sub-reach } & \multirow{3}{*}{ Raw } & \multicolumn{2}{|c|}{ Praloran sub-reach } \\
\hline & \multirow[t]{2}{*}{ Raw } & \multicolumn{2}{|c|}{ Thresholded DoD Estimate } & & Thresholded & timate \\
\hline & & \pm Error Volume & \% Error & & \pm Error Volume & $\%$ Error \\
\hline Total Volume of Erosion $\left(\mathrm{m}^{3}\right)$ & 216.365 & $198.040 \pm 50.527$ & $26 \%$ & 231.035 & $206.460 \pm 73.205$ & $35 \%$ \\
\hline Total Volume of Deposition $\left(\mathrm{m}^{3}\right)$ & 127.570 & $114.112 \pm 19.820$ & $17 \%$ & 158.440 & $139.511 \pm 28.804$ & $21 \%$ \\
\hline Total Net Volume Difference $\left(\mathrm{m}^{3}\right)$ & -88.795 & $-83.927 \pm 54.276$ & $-65 \%$ & -72.595 & $-66.949 \pm 78.668$ & $-118 \%$ \\
\hline
\end{tabular}

Table 3. Raw and thresholded volumes of geomorphic changes accounting for uncertainty for the Tagliamento river.

\begin{tabular}{|c|c|c|c|c|c|c|}
\hline & \multicolumn{3}{|c|}{ Cornino sub-reach } & \multicolumn{3}{|c|}{ Flagogna sub-reach } \\
\hline & \multirow[t]{2}{*}{ Raw } & \multicolumn{2}{|c|}{ Thresholded DoD Estimate } & \multirow[t]{2}{*}{ Raw } & \multicolumn{2}{|c|}{ Thresholded DoD Estimate } \\
\hline & & \pm Error Volume & $\%$ Error & & \pm Error Volume & $\%$ Error \\
\hline Total Volume of Erosion $\left(\mathrm{m}^{3}\right)$ & 767.006 & $744.173 \pm 89.317$ & $12 \%$ & 440.610 & $415.077 \pm 72.787$ & $18 \%$ \\
\hline Total Volume of Deposition (m³) & 523.068 & $503.779 \pm 61.277$ & $12 \%$ & 564.462 & $538.138 \pm 85.722$ & $16 \%$ \\
\hline Total Net Volume Difference $\left(\mathrm{m}^{3}\right)$ & -243.938 & $-240.394 \pm 108.316$ & $-45 \%$ & 123.852 & $123.061 \pm 112.456$ & $91 \%$ \\
\hline
\end{tabular}


the representation of the wet channel landforms, a volumetric rate closer to the real change can be achieved. The spatially variable assessment of the uncertainty through the production of error surfaces by combining the associated input DTMs (slope, point density and bathymetric points quality) regulated by the FIS rules has finally allowed to recover some information normally below the chosen uniform min LoD (minimum Level of Detection). The use of the probabilistic Bayesian updating for identifying coherent units of erosion and deposition (using the contiguity index) has also helped to recuperate low magnitude volumes of change. Even though the present study represents a very accurate and reliable attempt of geomorphic change estimation, further improvements could be carried out to reduce possible sources of error such as, in this case, small areas of vegetation interference.

Concerning the resulting sediment budget, we can observe a common deficit of sediment in the two sub-reaches of the Piave river, whereas in the Tagliamento river the situation seems to be more equilibrated with erosion dominating the budget in the first sub-reach and deposition in the second. In this sense, future management strategies accounting for the achievement of a sediment continuum should be though, especially for the Piave river, to re-establish a dynamic equilibrium in the fluvial environment.

\section{Conclusions}

The recent investigation of river dynamics relies always more on quantitative amounts of change to analyze the present condition of fluvial environments and choose the more effective restoration actions. The detection of the short-term geomorphic variations occurred as a consequence of the 2010 flood events through the proposed improved GCD analysis (evaluating also the bathymetric points quality) has demonstrated to be a reliable method to achieve precise volumetric estimates. These erosion and deposition trends can thus represent a trustworthy basis on which effective restoration measures can be undertaken.

\section{References}

Brasington J., Langham J., Rumsby B.T. 2003. Methodological sensitivity of morphometric estimates of coarse fluvial sediment transport. Geomorphology. 53: 299-316.

Comiti F., Da Canal M., Surian N., Mao L., Picco L., Lenzi M.A. 2011. Channel adjustments and vegetation cover dynamics in a large gravel bed river over the last 200 years. Geomorphology. 125: 147 159.

Devereux B., Amable G. 2009. Airborne LiDAR: instrumentation, data acquisition and handling. In: G.L. Heritage, A.R.G Large (ed.) Laser Scanning for the Environmental Sciences. Wiley-Blackwell, Chichester, UK.

Fuller I.C., Large A.R.G., Heritage G.L., Milan D.J., Charlton M.E. 2005. 35. Derivation of reach-scale sediment transfers in the River Coquet, Northumberland, UK. In: M. Blum, S. Marriott, S. Leclair (ed.) Fluvial sedimentology VII. : International Association of Sedimentologists Special Publ. N. 35, Wiley-Blackwell, Chichester, UK, pp 61-74.

Heritage G.L., Milan D.J. 2009. Terrestrial laser scanning of grain roughness in a gravel-bed river. Geomorphology. 113: 4 -11.

Hilldale R.C., Raff D. 2008. Assessing the ability of airborne LiDAR to map river bathymetry. Earth Surface Processes and Landforms. 33: 773-783.

Kaless G., Mao L., Lenzi M.A. 2013. Regime theories in gravel-bed rivers: models, controlling variables, and applications in disturbed Italian rivers. Hydrol. Process. (published online). DOI: 10.1002/hyp.9775.

Lane S.N., Westaway R.M., Hicks D.M. 2003. Estimation of erosion and deposition volumes in a large, gravel-bed, braided river using synoptic remote sensing. Earth Surface Processes and Landforms. 28: 249-271.

Mao L., Picco L., Cooper J., Lenzi M.A. (in preparation). How surface grain organization influences the relationship between grain size and roughness in gravel-bed rivers?

Marcus W.A., Fonstad M.A. 2008. Optical remote mapping of rivers at sub-meter resolutions and watershed extents. Earth Surface Processes and Landforms. 33: 4-24.

Milan D.J., Heritage G.L., Hetherington D. 2007. Application of a 3D laser scanner in the assessment of erosion and deposition volumes and channel change in a proglacial river. Earth Surface Processes and Landforms. 32: 1657-1674.

Milan D.J., Heritage G.L., Large A.R.G., Fuller I.C. 2011. Filtering spatial error from DEMs: Implications for morphological change estimation. Geomorphology. 125: 160-171.

Moretto J., Rigon E., Mao L., Picco L., Delai F., Lenzi M.A. 2012. Assessing morphological changes in gravel bed rivers using LiDAR data and colour bathymetry. Erosion and Sediment Yields in the Changing Environment, IAHS Publ. 356: 419-427.

Notabaert B., Verstraeten G., Govers G., Poesen J. 2008. Qualitative and quantitative applications of LiDAR imagery in fluvial geomorphology. Earth Surface Processes and Landforms. 34: 217-231.

Picco L., Mao L., Cavalli M., Buzzi E., Rainato R., Lenzi M.A. (submitted). Evaluating short-term morphological changes in a gravel-bed braided river using Terrestrial Laser Scanner. Geomorphology.

Wheaton J.M., Brasington J., Darby S.E., Sear D.A. 2010. Accounting for uncertainty in DEMs from repeat topographic surveys: improved sediment budgets. Earth Surface Processes and Landforms. 35: 136-156. 